\title{
Case Report: Hemorrhage into an Occult Spinal Ependymoma after Epidural Anesthesia
}

\author{
Peter G. Campbell MD \\ Thomas Jefferson University \\ Ashwini D. Sharan MD \\ Thomas Jefferson University \\ James S. Harrop MD \\ Thomas Jefferson University
}

Alex R. Vaccaro MD

Thomas Jefferson University Hospital and The Rothman Institute

John K. Ratliff MD

Thomas Jefferson University Follow this and additional works at: https://jdc.jefferson.edu/jhnj

Part of the Neurology Commons

Let us know how access to this document benefits you

\section{Recommended Citation}

Campbell MD, Peter G.; Sharan MD, Ashwini D.; Harrop MD, James S.; Vaccaro MD, Alex R.; and Ratliff MD, John K. (2008) "Case Report: Hemorrhage into an Occult Spinal Ependymoma after Epidural Anesthesia," JHN Journal: Vol. 4 : Iss. 1 , Article 2.

DOI: https://doi.org/10.29046/JHNJ.004.1.005

Available at: https://jdc.jefferson.edu/jhnj/vol4/iss1/2

This Article is brought to you for free and open access by the Jefferson Digital Commons. The Jefferson Digital Commons is a service of Thomas Jefferson University's Center for Teaching and Learning (CTL). The Commons is a showcase for Jefferson books and journals, peer-reviewed scholarly publications, unique historical collections from the University archives, and teaching tools. The Jefferson Digital Commons allows researchers and interested readers anywhere in the world to learn about and keep up to date with Jefferson scholarship. This article has been accepted for inclusion in JHN Journal by an authorized administrator of the Jefferson Digital Commons. For more information, please contact: JeffersonDigitalCommons@jefferson.edu. 


\section{Case Report: Hemorrhage into an Occult Spinal Ependymoma after Epidural Anesthesia}

Peter G. Campbell, MD1, Ashwini D. Sharan, MD1, James S. Harrop, MD, Alexander R. Vaccaro, MD', ${ }^{1,}$ John K. Ratliff, MD', 2

${ }^{1}$ Department of Neurological Surgery, Thomas Jefferson University Hospital, Philadelphia, PA ${ }^{2}$ Department of Orthopedic Surgery, Thomas Jefferson University Hospital, Philadelphia, PA

Originally published in The Open Surgery Journal (vol. 2, pp. 18-20, 2008), an Open Access Journal (Bentham Science Publishers Ltd.). Republished with permission.

\section{Abstract}

Summary of Background Data: Five cases of hemorrhage into a spinal neoplasm after spinal or epidural anesthesia are reported in the literature. Presentation ranges from severe low back pain to acute cauda equina syndrome.

Methods: A case study of a patient who hemorrhaged into an intradural, extramedullary spinal cord mass was performed. A detailed literature review is also provided.

Results: A 27 year old female underwent epidural anesthesia for Cesarean section delivery. She presented with a 3 week history of increasing low back pain with bilateral radiculopathy. Imaging studies revealed a large hemorrhagic intradural mass compressing the lower conus medullaris and cauda equina, which operatively was confirmed to be a myxopapillary ependymoma.

Conclusions: We report a case of hemorrhage into a previously unrecognized ependymoma after epidural anesthesia. Underlying tumors may rarely complicate regional anesthesia in the lumbar spine.

\section{Keywords}

Ependymoma, epidural anesthesia, spinal anesthesia, hemorrhage, myxopapillary ependymoma.

\section{Abbreviation list}

MRI: Magnetic resonance imaging

\section{Introduction}

Epidural anesthesia is a procedure which is well tolerated and has a low incidence of adverse events. In performing caesarean sections, regional anesthesia (spinal or epidural) is the preferred modality for anesthetic delivery ${ }^{7}$. Although rare with continuous epidural anesthesia, epidural hematomas have been reported to occur with an incidence between 1:150,000 and 1:190,000 ${ }^{10}$. An underlying bleeding diathesis has been implicated as a causative factor. We present the sixth reported case of hemorrhage into an occult intradural neoplasm after spinal or epidural anesthesia. Similar lesions have not been reported in the recent spine literature. ${ }^{1,2,3,5,8}$

\section{Case Report}

A 27-year-old gravida 1, para 0 patient underwent a Caesarean section with epidural anesthesia without difficulty. She was discharged home with a healthy infant on post operative day two. Three days after the procedure the patient noted a moderate degree of low back pain, which was initially attributed to ligamentous strain. Conservatively therapy, consisting of bed rest and analgesics, failed to provide symptomatic relief. The symptoms persisted and the patient progressed over the following three weeks, noting worsening low back pain radiating to the legs. The patient then presented to the emergency department, where she described severe low back pain radiating into both lower extremities. Her past medical history was insignificant. She denied any history of coagulopathy, heavy menses or any contributory family history. A thorough neurological exam revealed intact motor strength sensation, with normal deep tendon reflexes and an absent Babinski's sign. A rectal exam revealed normal anal sphincter tone and volition.

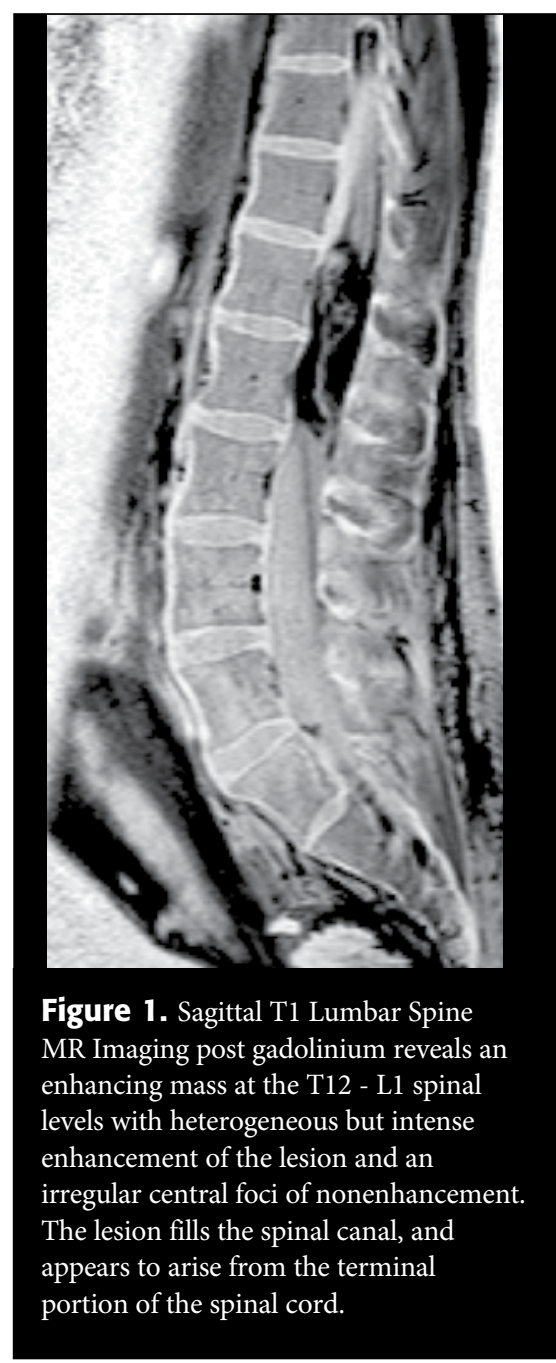

\section{Investigations}

No hematological abnormalities were noted on laboratory examination. MR Imaging of the lumbar spine with and without gadolinium revealed an oblong intradural mass at T12-L1 with intense peripheral enhancement and irregular central nonenhancement was noted (Figures 1-3). Complete MR imaging of the neuroaxis showed no additional lesions. 


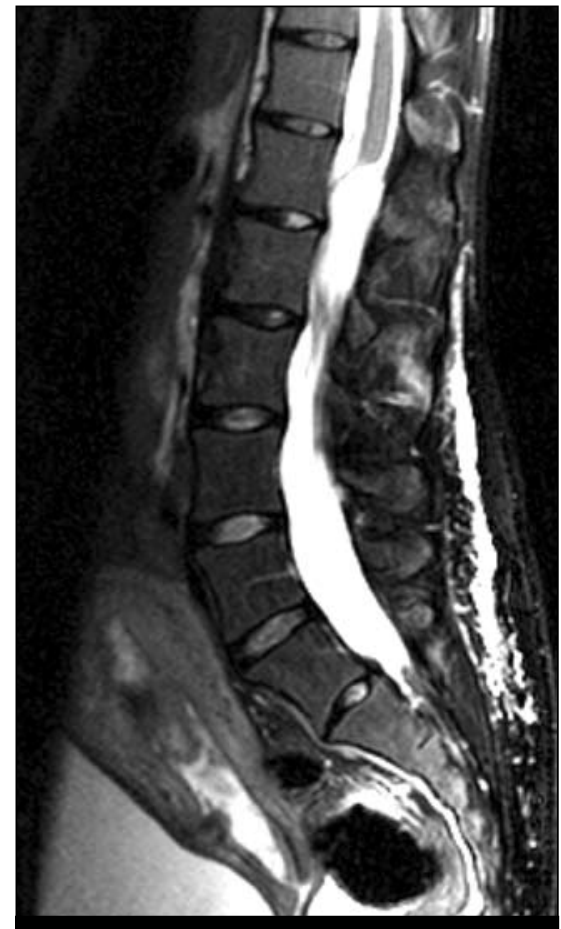

Figure 2. Sagittal T2 Lumbar Spine MR Imaging reveals an oblong intradural mass $6.1 \times 1.9 \times 1.7 \mathrm{~cm}$ in the craniocaudal, transverse, and anterioposterior dimensions. Bright imaging CSF appears above and below the lesion. Again, the lesion appears to begin at the terminal portion of the spinal cord.

\section{Treatment}

The patient underwent a T12 to L2 laminectomy. Intraoperatively, an intradural mass adherent to the cauda equina and filum terminale with some intratumoral hemorrhage was removed. A gross total resection was accomplished.

\section{Pathology}

Finalpathologicanalysisofthesurgicalspecimen revealed a myxopapillary ependymoma.

\section{Postoperative Course}

The patient made a full recovery. She manifested initial urinary retention, which resolved with the discontinuation of narcotics. Postoperative MR Imaging revealed no evidence of residual tumor.

\section{Discussion}

Extramedullary spinal cord tumors may be intradural, extradural, or a combination of the two. Extradural tumors account for roughly $30 \%$ of spinal cord neoplasms while intradural

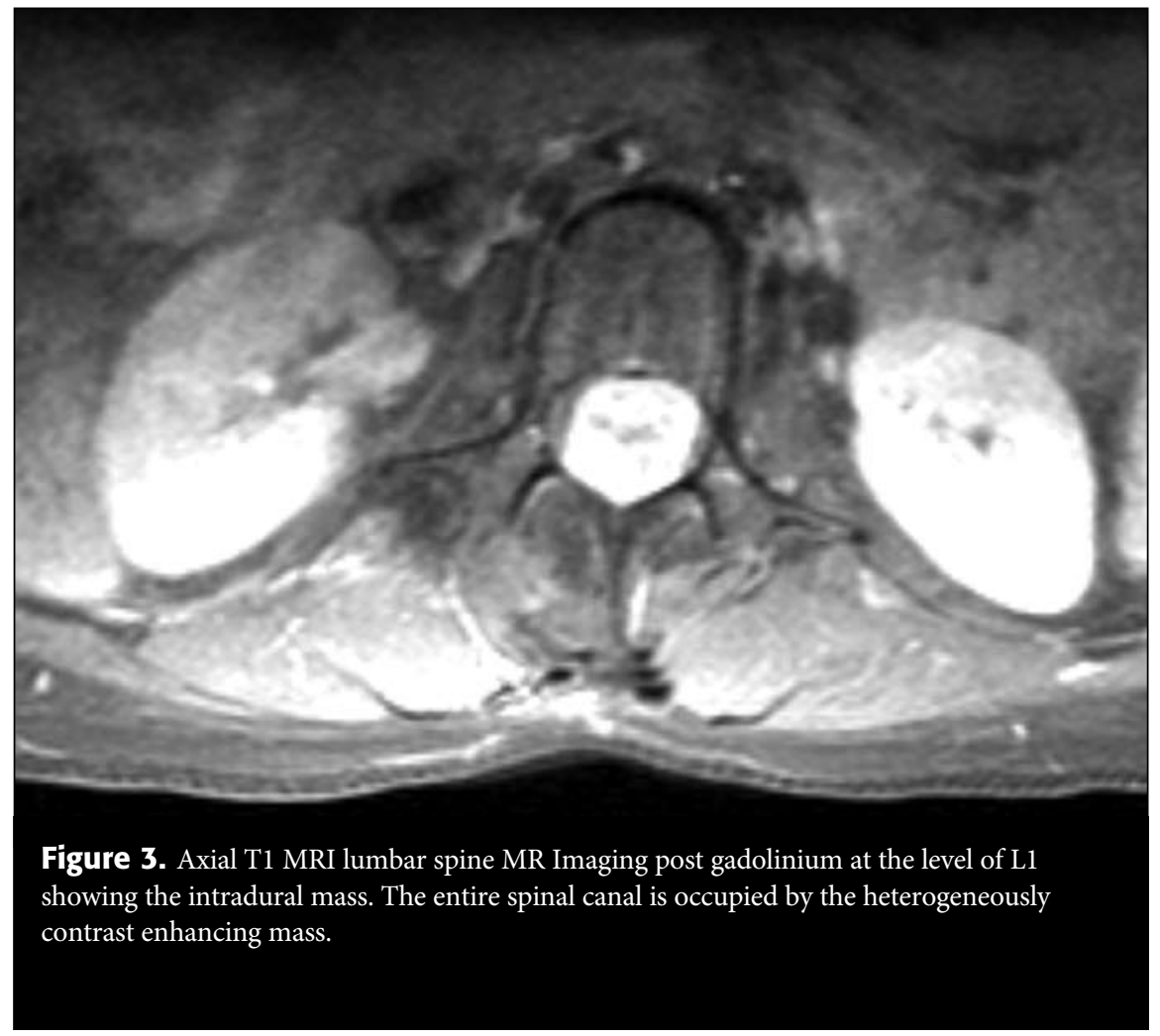

extramedullary tumors are responsible for approximately 40 to $50 \% .{ }^{4}$ Intradural spinal cord tumors are uncommon with an incidence of about 3-10 per 100,000 individuals. These tumors occur predominately in the third and fourth decades of life. ${ }^{9}$ The most common extramedullary spinal cord tumors are nerve sheath tumors, meningiomas and filum terminale ependymomas. Ependymomas are the most common gliomas of the lower cord, conus and filum terminale; the myxopapillary histological variant is most common. Approximately $40 \%$ of all spinal ependymomas arise within the proximal intradural filum terminale. ${ }^{4}$ Back pain is the most common presenting symptom, with neurological compromise rare secondary to the adaptive compressibility of the surrounding structures. Mork and Loken report that in $82 \%$ of patients with spinal ependymoma, symptoms were present for more than 1 year before the diagnosis was achieved. ${ }^{6}$ Treatment for these lesions is typically en bloc surgical resection. ${ }^{9}$ Radiation therapy is reserved for recurrent disease or aggressive histopathology, with regular radiographic follow-up recommended. In cases of subtotal resection, radiotherapy may be required.
Epidural anesthesia is an effective procedure with a low incidence of complications. Neurological compromise following epidural anesthesia, while highly uncommon, is the most concerning potential sequela of the procedure. Epidural hematomas may rarely occur during continuous epidural anesthesia, with a reported incidence between 1:150,000 and $1: 190,000 .^{10}$ The majority of these cases are believed due to a primary coagulopathy.

Rarely, hemorrhage from an occult spinal mass occurs in an asymptomatic patient receiving epidural anesthesia. The first case of intratumoral bleeding in an asymptomatic patient after attempted epidural anesthesia was reported in 1984. A patient developed low back pain, bladder dysfunction, worsening motor and sensory function in both legs three days after epidural analgesia. ${ }^{8}$ Since then, four additional cases involving hemorrhage into an occult neoplasm by regional lumbar spine anesthesia have been reported. Three cases involve epidural anesthesia ${ }^{1,3,5}$ and one was caused by a subarachnoid injection of anesthetic. In each of these cases, the underlying lesion was an ependymoma. In our case and one other the only complaint prior to neurosurgical intervention was severe low back pain with increasing bilateral radicular 
Table 1. Reports of Hemorrhage into a Neoplasm After Regional Spinal Anesthesia

\begin{tabular}{|c|c|c|c|c|c|}
\hline Author & Year & Patient & Surgery & Anesthesia & Tumor \\
\hline Antoniadis et al..$^{1}$ & 1985 & 79 , female & $\begin{array}{l}\text { Removal of femoral } \\
\text { osteosynthesis }\end{array}$ & Epidural & Ependymoma \\
\hline Bredtmann et al. ${ }^{2}$ & 1989 & 58 , male & & Subarachnoid & Ependymoma \\
\hline Jaeger et al. ${ }^{3}$ & 2002 & 28 , female & Cesarian section & Subarachnoid & Ependymoma \\
\hline Martin et al. ${ }^{5}$ & 1992 & 31 , female & Cesarian section & Epidural & Ependymoma \\
\hline Roscoe et al. ${ }^{8}$ & 1984 & 24 , female & Cesarian section & Epidural & Ependymoma \\
\hline
\end{tabular}

pain. ${ }^{5}$ In the remaining reports, a component of lower extremity weakness and bowel or bladder dysfunction was noted. More severe presentations are reported: Jaeger et al. detailed a similar case with a lesion in a comparable area and described neurological deficits progressing to paraplegia within 24 hours. ${ }^{3}$ Previously reported cases are reviewed in Table 1.

\section{Conclusion}

Occult spinal masses should be considered in the differential diagnosis in a patient with new onset neurological deficits or unusual pain complaints after spinal or epidural anesthesia. MR imaging of the lower thoracic and lumbar spine may be useful in evaluation of these symptoms.

\section{References}

1. Antoniadis G. Richter HP. Schachenmayr W. Hemorrhage into a spinal ependymoma after peridural anesthesia. Neurosurgery. 1985; 16(5): 669-71.

2. Bredtmann RD, Wright J, Weissflog M. A space-occupying hemorrhage following spinal anesthesia in the presence of an undiagnosed small spinal tumor (ependymoma). Reg Anaesth. 1989; 12(2): 38-40.

3. Jaeger M, Rickels E, Schmidt A, et al. Lumbar ependymoma presenting with paraplegia following attempted spinal anaesthesia. Br J Anaesth. 2002; 88(3): 438-40.

4. Kuntz C, Shaffrey CI, Wolcott WP. Approach to the Patient and Medical Management of Spinal Disorders. In: Winn HR, editor. Youmans Neurological Surgery, Vol 4. Philadelphia, Saunders. 2004: 4289-4326.

5. Martin HB, Gibbons JJ, Bucholz RD. An unusual presentation of spinal cord tumor after epidural anesthesia. Anesthesia \& Analgesia 1992; 75(5): 844-6.

6. Mork SJ, Loken AC. Ependymoma: a follow-up study of 101 cases. Cancer. 1977; 40(2): 907-15.

7. Ng K. Parsons J. Cyna AM. Middleton P. Spinal versus epidural anaesthesia for caesarean section. Cochrane Database of Systematic Reviews, 2, CD003765, 2004.
8. Roscoe MW, Barrington TW. Acute spinal subdural hematoma. A case report and review of literature. Spine. 1984;9(7):672-5

9. Stein BM, McCormick PC. Spinal intradural tumors. In Wilkins RH, Rengachary SS, eds. Neurosurgery, Vol 2. New York, McGraw-Hill. 1996: 1769-1781.

10. Wulf $\mathrm{H}$. Epidural anesthesia and spinal haematoma. Can J Anaesth. 1996;43:1260-1272. 